\title{
Rethinking ephemeral architecture. Advanced geometry for citizen-managed spaces.
}

\author{
Martín-Pastor, Andrés ${ }^{(1, *)}$, Martín-Mariscal, Amanda ${ }^{(2)}$, López-Martínez, \\ Alicia ${ }^{(3)}$ \\ (1)Department of Graphic Engineering, University of Sevilla. \\ Instituto Universitario de Arquitectura y Ciencias de la Construcción \\ archiamp@us.es, +0034 618069634 \\ (2) University of Sevilla. \\ Instituto Universitario de Arquitectura y Ciencias de la Construcción \\ (3) University of Sevilla
}

\section{Summary}

In recent years there have been a high amount of citizen initiatives that address the complex problems of the contemporary city. There are empty or disused spaces that have been reused for urban gardens, for social use, to encourage integration and civic activities activation, etc. Traditional architectural processes do not provide realistic solutions to these initiatives that, along with limited financial resources, have led to the emergence of architectures and self-constructed facilities, almost as an emergency mode, without necessary planning, media and constructive knowledge. The democratization of technology, thanks to laboratories of digital production, combined with knowledge of the properties of different surfaces through the CAD-CAM tools, offers new opportunities for the development of a lightweight, flexible and low impact architecture, very according to the needs of citizens' initiatives that naturally arise in our cities. The new existing scenario contemplates the figure of the architect, or engineer, not only as an agent of the market, but as a professional able to propose efficient solutions to problems from within, bringing their specific knowledge and serving as bridges between the new technological solutions and the challenges of society.

Keywords Ephemeral architecture; Eco-efficiency; Digital Fabrication; Collective Creativity; Advanced Geometry. 
Martín-Pastor, A.; Martín-Mariscal, A.; López-Martínez, A.

\section{Introduction}

At the current moment of crisis, the traditional model of architectural production is strongly questioned due to its anti-ecological character and the negative imprint that this constructive dynamic has left us in the city. We refer to an architecture set by markets and whose processes are performed top-to-down at all levels. A trend that presupposes that the processes of innovation and technology resulting from them are applied mainly from the construction industry, then made profitable from the commercial side.

From this premise, the problems of the city are also understood - from topas a set of transient imbalances that can only be addressed and resolved by accepting the mechanisms of the current system. Some problems that, according to Sennett (2008), are very complex to analyze and even more to solve, but whose consequences can be seen every day in our cities: degraded empty urbans, contamination due to unfinished works public spaces of impossible habitability, etc.

Precisely, to address this crossroad and from a totally different approach, citizen managing spaces offer a management system of organization that intended to answer to many of these problems -not all- we suffer in the current city. Social participation is important here, being the citizen who actively and collaboratively participates in the decision-making and projects to be undertaken. These groups have very diverse characteristics and different needs. Some contemplate the use of outdoor activities, since the main character of their activity takes place at precisely the outside, as the case of urban gardens- or because the activity itself necessarily involves the processing and use of that space according to the architectural action, - as in the regeneration empty urbans - architecture understood here as in its broadest sense of "transformation of the human habitat" (Martín-Mariscal 2016). In this sense it is interested to remember the words of Estalella (2015):

The cities are mutating from one side to another of the globe. People that previously just transited through their streets or walked gardens, lodge in them to furnish squares and occupy lots. A form of citizen urbanism emerges, through which the urban space is redesigned on the street and from the street.

\section{Self-building or Ephemeral Architecture?}

The highlighted aspect, and which is linked to sustainable construction processes, is the formula already used by many of these groups called ephemeral architecture. This architectural style is suitable not only to solve the problem of lack of resources of promoters and managers, but also to reasonably cope —or perhaps in 
the unique way possible- legal problems arising from realizing an architectur$\mathrm{al} /$ structural project on a floor without any license, either a disused land, public or other. The nature of ephemeral architecture - intentionally understood as simple furniture that is assembled and disassembled without damaging the environment where it is located - lacks of application of either mandatory compliance or constructive recommendation rules.

\subsection{Digital craft vs improvised manufacturing}

At the same time, we have observed that collective and agent drivers of these citizen initiatives frequently have few tools to promote the full phase of design, production and assembly of architectural facilities - ephemeral or non-ephemeral, simply self-built - optimized to develop their activities (Martín-Mariscal 2016). Scarce economic resources have led, in some cases, facilities almost as emergency mode, without planning, resources and knowledge to develop architecture according to different needs. Similarly, the character of innovation in architecture is appreciated and lived, for some groups, as something external and outside their means and possibilities, assuming —-sometimes almost like a creed - improvising manufacturing and low technological character recycling as an environmental brand image even more outsider, rejecting everything that is not natural. Indeed, a CAD program, a CNC milling machine and a robotic arm could be understood as something artificial, alien to the human and to the craft. In contrast to this theory, the digital craftsmanship and built digital materiality concept (Chiarella, Pastor Martín 2015), which later will be developed, is established.

The moment of crisis - or change - in which we live provides new opportunities recently unimaginable. One of these opportunities is access to technology and laboratories of digital production, allowing work on the basis of innovation, not only from the market sector, but also from the creation of knowledge produced in universities and researching groups associated to them. The outlook notes to how these new production processes, applied to architecture, can overcome some inherent challenges of the current time (Martín-Mariscal et al 2016). Thus, numerical control machines, widely used in industrial design, are slowly incorporated into the architecture offering the possibility of manufacturing without intermediaries (Meredith, Kotronis 2012). These new-production architectural processes face the challenge of accompanying the complexity of the projects generated by informatics tools to prevent that complexity comes from execution besides complex geometries. Digital materiality starts from graphic thinking with digital processes, proposing new relationships between the architectural object and its representation (Chiarella, Martín-Pastor et al 2016). 


\section{A project of Ephemeral Architecture}

According to these social premises and framed within objective limits, the challenge we propose is to develop a model of design-production-assembly of a lowimpact architecture in these citizen-managed spaces, using digital tools - Parametric Design and Digital Fabrication-, minimizing cost and impact of such architectural interventions. In short, perform a low-cost and high technological character architecture — Low-Cost and High Tech — involving low investment for their promoters but that maximizes efficiency and sustainability in all processes, incorporating optimized production and self-assembly forms. A productive logic that already exists in other fields, precisely in furniture design. The most obvious example is Ikea furniture, of which we have taken several references in the level of optimization and differentiation of teamwork: design, manufacturing, and assembly, the latter being accomplished by the end user.

Previous research on the use of surfaces (Casale et al 2013) and its use in ephemeral pavilions, places us in an appropriate position to continue the research we have developed over the past two years, optimizing the design, reducing costs and impact of such facilities. Ephemeral architecture that proposed is composed of developable surfaces, those that can be deployed in the plane. Proposed prototypes are self-supporting skins made by a thin sheet of material — wood - approximately $6 \mathrm{~mm}$ thick. With parametric algorithms and CAD-CAM technology it is possible to deploy these complex surfaces in flat pieces. They are assembled on the ground, like a big puzzle, then curving from the plane into space to acquire its final shape and strength, thanks not the thickness but the geometry itself (NarvaezRodriguez et al 2014) (Martín-Pastor 2016 ).

The production of this type of architecture considers creating its own manual of Ikea type assembly, and part of the research is to soon become the architectural object into a real piece of furniture that can be self-built by any group of people. Part of the novelty of the proposal also influence on rethinking the use and enjoyment of certain spaces through so light interventions and so low impact, excluding the rules of architectural occupation, even true architectural structures.

\subsection{Previous Experience}

Previous experience of design, manufacture and installation of this type of ephemeral architecture consists of five experimental pavilions in the field of geometry research — architectural geometry — and Digital Fabrication (Fig.1). These pavilions are: The Caterpillar Gallery, made in University of Sevilla ETSIE in February 2014; The Cocoon Gallery, at National University of Colombia (UNAL) Medellin in August 2014; The SSFS Pavilion-Santa Fe, FADU at Litoral University, Santa Fe, Argentina, from March $26^{\text {th }}$ to April $27^{\text {th }}$, 2015; The Butterfly Gallery- 
Helical Surfaces in UFRJ at Federal University of Rio de Janeiro, Brazil, from August $4^{\text {th }}-14^{\text {th }} 2015$; and SSFS Fablab-Pavilion Seville, raised at Seville's Plaza Nueva in September 2015 (installation awarded with 2nd and 3rd Emporia National Award in the categories of "Innovation in Ephemeral Architecture" and "Green Stand").
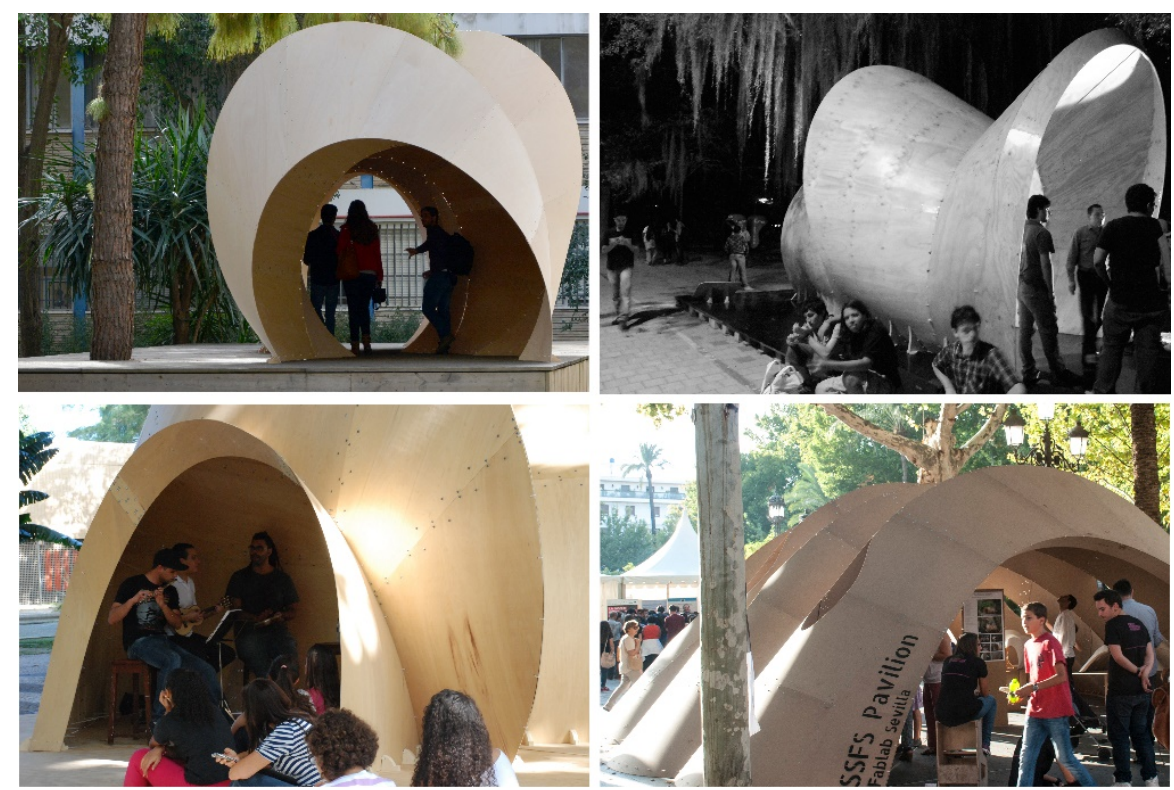

Fig. 1. Top-left: Caterpillar Gallery. Top-right: Cocoon Gallery. Bottom-left: Butterfly GalleryHelical Surfaces; Bottom-right: SSFS-Fablab-Pavilion Seville.

This type of architecture, besides being an example of realization of Digital Fabrication processes described above, provides architectural and functional characteristics appropriate to be enjoyed in activities developed in the areas of citizenmanaged spaces of our cities.

\subsection{Innovation and sustainability. Architecture as Digital Fabrication furniture}

As discussed above, we propose the development of a furniture type of architecture. Bringing these ideas from the world of industrial furniture to the world of architecture has clear advantages from the point of view of sustainability. From the point of view of design the classic concept of the construction process, where the 
architect is the author of the two - dimensional graphic information and a group of specialized craftsmen who execute changes are who execute -with more or less mastery - what was previously defined in the project. Gramazio and Kohler (2008), establish digital materiality in the existing complex interweave between computer programming, 3D construction —or digital modeling-, data and matter, at different stages of the architectural project. The new concept of digital craftsmanship emphasizes the figure of the architect as head of the interaction of all digital processes related to design and production (Fig.2).

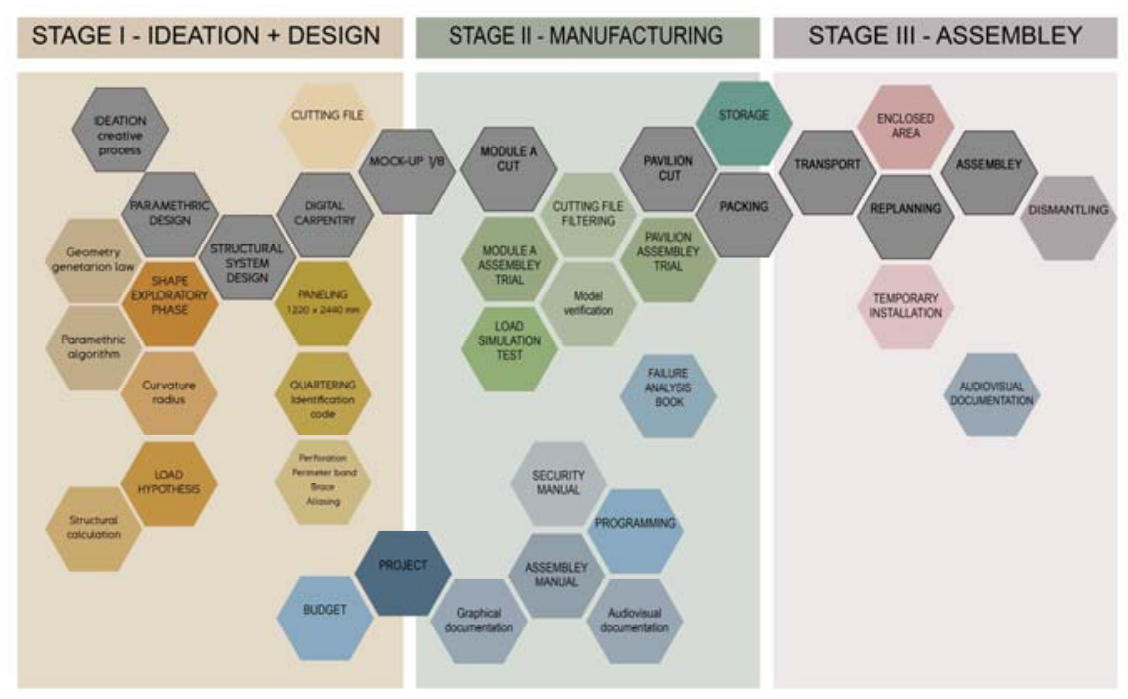

Fig. 2. This graph summarizes the three main phases of Digital Fabrication process: design, manufacturing and assembly, showing the various feedbacks that occur between them (Image created by authors).

In the Digital Fabrication process, robotic cut machine - CNC or hand Robot - handles the execution and machining work, minimizing the margin of error and getting cuts of very high precision. Human error is greatly reduced, focusing on monitoring and process optimization.

The optimized Digital Fabrication process will use the closer digital fabrication laboratory to the installation location, thus minimizing the energy costs and transport CO2 emissions and giving preference to the local economy. Furthermore, a sustainable process must have priority in the use of materials of the area, with special attention to recycled and local products, thereby reducing the ecological footprint.

The architecture will be entirely reduced to a set of elements where does not exceed or lack any part or any screws. Thus, only necessary parts are produced, minimizing waste generated in the manufacturing process. Similarly, the packag- 
ing process ensures that only truly necessary material is transferred to the installation site, being a dry type construction that generates zero waste.

The assembly — or dismantling — is done by the end users, saving costs in the process both in the displacement of specialized personnel or machinery (Fig.3). Maintenance spending in this architectural model is almost zero as it is a set of pieces defined by a code and replaceable by the user, who is in possession of the cutting file and the ability to reproduce it again in the laboratory of Digital Fabrication of his local network. Finally, the proposed architecture is completely removable, transportable and usable in other places, so no physical trace occurs in the place where it was located.
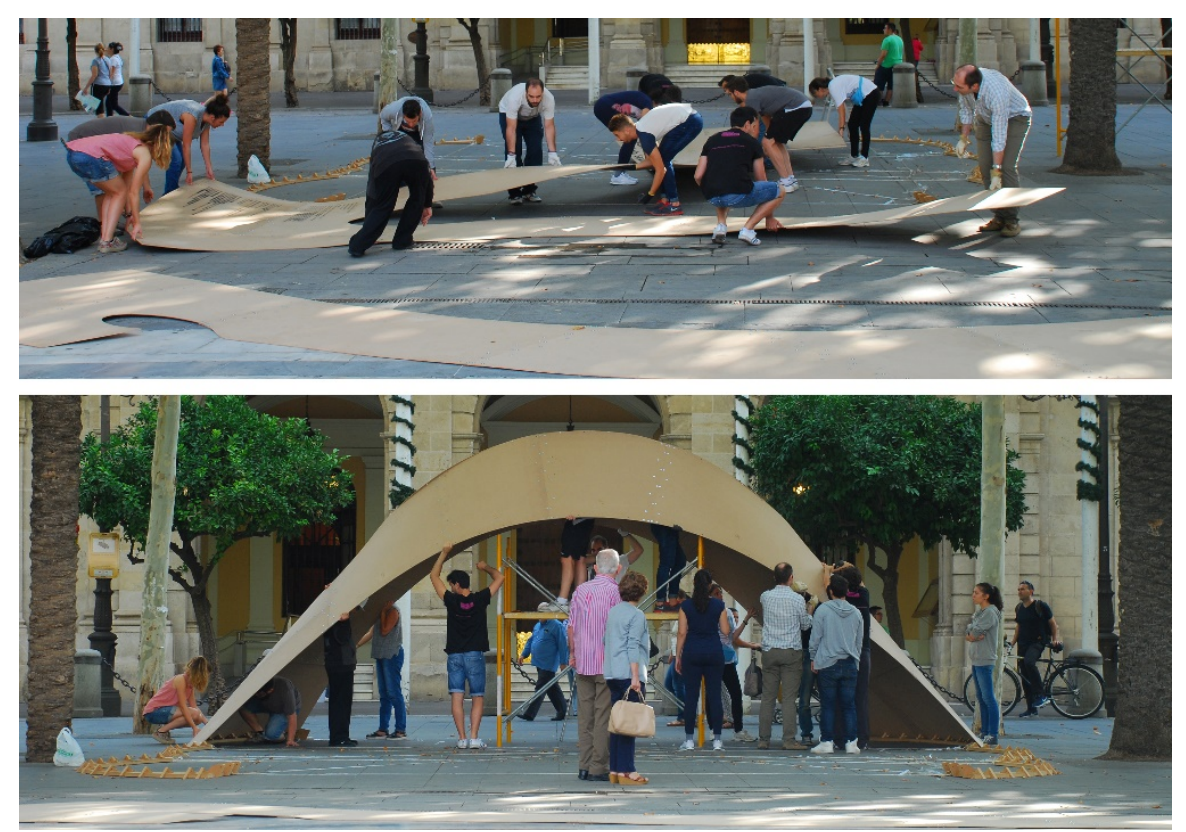

Fig. 3. Different stages of assembly of Fablab SSFS Pavilion Plaza Nueva in Seville

\section{Results and lines for improvement}

The proposed system tries to give architectural solutions from the logic of few material resources - a thin sheet of material — and minimum installation cost. The challenge of this project is to make progress on problems detected in previous experiences and to propose a truly useful model for use in public citizen-managed spaces.

Previous experiences faced problems such as the high number of workers required for assembly. This was due to the weight of each ring, oscillating around 80 
$\mathrm{kg}$. To move these pieces two teams of 7 people were needed, one (assemblers) to move the material and the second one (aid) to lift and bend it. The weight problem is due in part to the type of material used, wood and its variants, either on plywood or on medium density boards. Therefore, it would be interesting to investigate the possibility of using new materials to reduce this type of difficulties.

Managing to reduce the number of assemblers and aids involves research work in designing and optimizing geometries in material efficiency. We propose to investigate the use of recycled materials and recycled foams to reduce the density of the material while other properties are held constant as the material active tension or bending strength. In this regard, another difficulty has been the material unwinding over time, which has led to the appearance of deformations in the structure. We have thought to address this situation from two different perspectives: using materials that do not develop unwinding, and generating the meeting of surfaces to avoid bi-tangency points, due that this leads to weakness of the material over time.

Also, from the point of view of building systems, assembly method developed previously by nylon screws and flanges to suit unspecialized mounting personal must be improved. On the other hand, being objects dedicated to be installed in public space, these projects must be sensitive to the pavement. An important part of the research will consist on articulating support and tightening systems that allow this condition.

Therefore, it is proposed to advance the design of Digital Fabrication process from three different perspectives: 1 - Design in material geometry, understanding it as flat sheets that are curved in space, seeking efficiency. 2- Design in purifying manufacturing processes. 3- Design in the detailed description of each assembly stage.

This entails an exhaustive study of the project on several levels:

1. Materials, optimizing efficiency.

2. Advanced Geometry of developable surfaces.

3. Methods of structural calculation of self-supporting structural skins.

4. Investigation of shape and support systems.

5. Construction systems related to assembly and installation.

6. Process optimization.

7. Graphical expression, minimizing errors in assembly (Fig.4). 


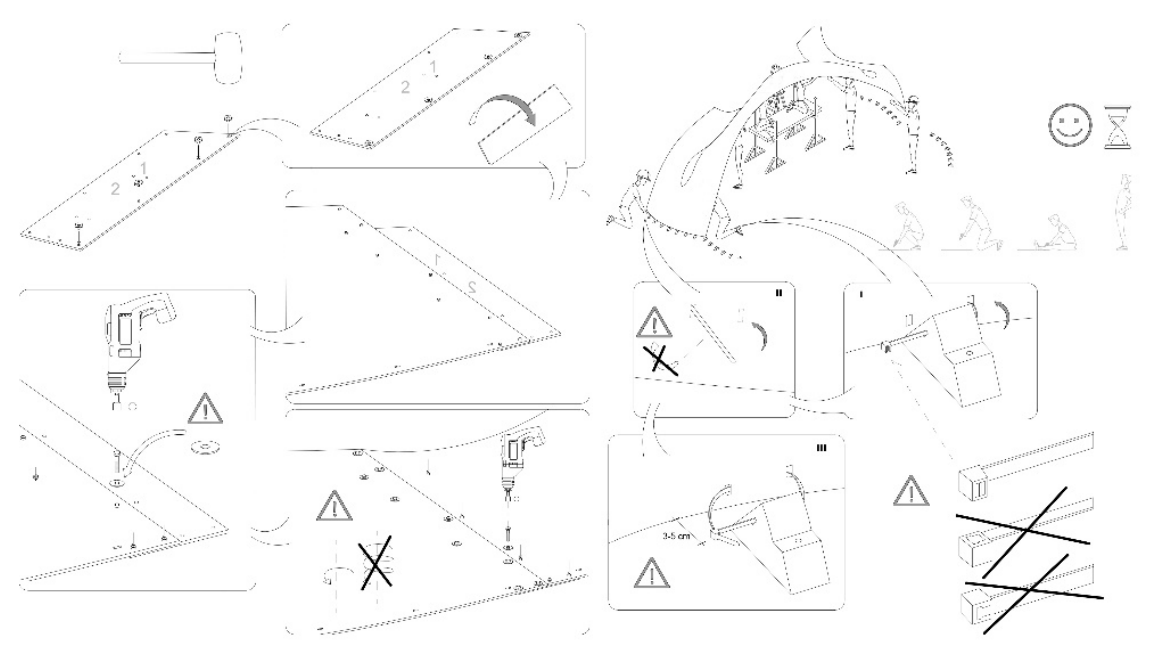

Fig. 4. An example of Assembly Manual proposed by Helena Santos Calvo, for SSFS-Pavilion. End of Grade Project illustration titled: Optimization of the assembly phase. Ephemeral pavilions of Digital Fabrication and lightweight materials. PFG 2015-2016, ETSIE, University of Sevilla.

\section{Conclusions and discussion. A reflection on the role of the architect}

As discussed, it is proposed to define an easy to assemble, low cost and reusable model of ephemeral architecture, whose recipients are citizens and citizenmanaged spaces. In this project the architect becomes the qualified mediator who uses his expertise to propose efficient architectural solutions adapted to the needs of a social collective. To do so, collective creativity or the possibilities for innovation or industrialized manufacturing are included, allowing access to Digital Fabrication laboratories. However, he refuses to be allied of an architecture based on work improvisation and low efficiency systems, while also does not demands results or unrealistic responses to people or unskilled collectives. Therefore, and sensitive to the underlying problems of these groups, a model of architectural production is proposed that leads to a product of unique architectural design. A furniture type, low-cost and high-tech architecture that exceeds improvisation and unskilled self-construction and proposes a real alternative to the architectural market.

There are interesting opportunities for architects, mainly to reinvent the process of design and manufacturing, and to foresee the integration of technology at home so that it responds to the needs and values of its inhabitants and demographic, health and energy challenges of society. In the process of drastically improving the quality of the built environment, we can even create a more central and important role for the architect of today. (Bernstein 2011, p.113) 


\section{Acknowledgements}

The Caterpillar Gallery. Authors and project design: Roberto NarvaezRodríguez, Andrés Martín-Pastor, (In collaboration: Infante-Pereda Margarita Maria Aguilar-Alejandre). Manufacture equipment FablabSevilla. Assembly: Teachers and students of ETSIE Schools and ETSA, University of Sevilla. Collaboration: Department of Engineering University of Sevilla

The Coccon Gallery. Project design Andrés Martín-Pastor and Roberto Narváez-Rodríguez. Manufacturing: Equipment FablabUnal Medellin. Execution and assembly: Architecture students UNAL UNAL Medellin and Manizales. Coordination: Es-strained Media Representation, Faculty of Architecture. Co-Unal Medellin Colombia. Collaboration: Extra. Grafica Engineering Equipment FablabSevilla.

SSFS Pavilion - Santa Fe Design and Project: Andrés Martín-Pastor, Roberto Narvaez-Rodriguez. Co-parametric design: Exposito Juan Bejarano. Academic Coordination and management: Mauro Chiarella. Master Program in Architecture, Fadu, Universidad Nacional del Litoral. Production and assembly: Students and teachers pro-Master of Architecture, Fadu. Collaboration: Extra. Graphic Engineering University of Sevilla, ETSIE Equipment FablabSevilla.

The Butterfly Gallery-Helical Surfaces. Project design Andrés Martín-Pastor, Juan Expósito Bejarano. Coordination: Maria Angela. Manufacturing: LAMO3D, Focus Design. Mounting: collaborative between teachers and students of the UFRJ. Collaboration: Extra. Graphic Engineering University of Sevilla, ETSIE Equipment FablabSevilla.

SSFS Pavilion - FablabSevilla. Project design Andrés Martín-Pastor, Juan Expósito Bejarano and Roberto Rodriguez Narvaez. Manufacturing: FabLabSevilla. Production Chief: Daniel del Valle. Mounting: collaborative between teachers and students of the ETSIE, FabLabSevilla and Edificalab. Collaboration: Extra. Graphic Engineering University of Sevilla, ETSIE Equipment FablabSevilla.

\section{Citations and References}

Bernstein P, Deamer P (2010) Building (in) the future: Recasting labor in architecture. Yale School of Architecture, New Haven.

CasaleA, Valenti GM, Calvano M et al (2013) Surfaces: Concept, Design, Parametric Modeling and Prototyping. NexusNetw J 15: 271. doi:10.1007/s00004-013-0146-8

Chiarella M, Martín-Pastor A (2015) Pensamiento Gráfico y Diseño Colaborativo. Geometríasdesarrollables en composiciones plegadas Arquitectónicas. In: Proceedings of the XIX Conference of the Iberoamerican Society of Digital Graphics 2015. [Blucher Design Proceedings, v.2, n.3]. Blucher, São Paulo, pp 702-707, doi: 10.5151/despro-sigradi2015-110107 
Repensando la Arquitectura Efímera. Geometría Avanzada / III CICSE

Chiarella M, Martín-Pastor A, et al (2016) Graphic and Digital Thought Processes. Three cases of digital materiality built (COCOON / Colombia, BANCAPAR / Chile, SSFS / Argentina). In: Proceedings of the XVI International Congress of Architectural EGA 2016 [n.16]. Foundation University of Alcalá, Alcalá de Henares, pp 763-770[http://ega2016.com/wpcontent/uploads/2016/06/Libro_EGA2016_Tomo_II.pdf]

Estalella A (2015) Collective architecture: Another urban sensibility. Retrieved fromhttp://www.prototyping.es/destacado/colectivos-de-arquitectura-otra-sensibilidad-urbana

Gramazio F, Kohler M (2008) Digital Materiality in Architecture. Lars Müller, Baden

Martín-Mariscal A (2016) Collective Creativity. Processes of Contemporary Architecture in Contexts of Complexity. Disertation, University of Sevilla

Martín-Mariscal A, Martín-Pastor A, López-Martínez A, et al (2016) Advanced Geometry for public spaces management. In: Proceedings of the XX Conference of the Iberoamerican Society of Digital Graphics 2016, Blucher, São Paulo (In press)

Martín-Pastor A (2016) A return to the fundamentals of geometry. The Butterfly Gallery, geometric strategies for Digital Fabrication. PROARQ notebooks. Journal of Architecture and Urbanism 2016 [n.25]. UFRJ Post-graduation Program in Architecture, Rio de Janeiro, pp 230 [http://cadernos.proarq.fau.ufrj.br/public/docs/cadernosproarq25.pdf ]

Meredith N, Kotronis J(2012) Self-Detailing and Self-Documenting Systems Systems for Wood Fabrication: The BurjKhalifa. In Advances in Architectural Geometry. TU Wien, Vienna, pp 185-198

Narváez-Rodríguez R, Martín-Pastor A, Aguilar-Alexandre M (2014) The Caterpillar Gallery: Quadric Surface Theorems, Parametric Design and Digital Fabrication. In: Block, P, Knippers, J, et al (ed) Advances in Architectural Geometry 2014. Springer, pp 309-322, doi: 10.1007/978-3-319-11418-7_20

Sennett R (2008) The craftsman. Yale University Press, New Haven 